\title{
ORGANIZACIJSKA OBILJEŽJA PROIZVOĐAČA KONZUMNIH JAJA U HRVATSKOJ
}

\author{
Ana Crnčan, Lari Hadelan, Igor Kralik, Jelena Kristić
}

\begin{abstract}
Sažetak
Cilj rada bio je analizirati proizvodno-organizacijsku strukturu gospodarstva čija je djelatnost proizvodnja jaja kako bi se utvrdila njihova razvojna perspektiva. Za prikupljanje podataka o proizvodno-organizacijskim obilježjima korištena je metoda ankete. Ispitivanje je obuhvatilo proizvođače konzumnih jaja upisane u Upisnik farmi kokoši nesilica na području Republike Hrvatske. Najveći broj gospodarstava, 38,10\%, djelatnost proizvodnje jaja obavlja kao samostalna gospodarska jedinica temeljena na vlasništvu i uporabi proizvodnih resursa, odnosno kao obiteljsko poljoprivredno gospodarstvo. Od četiri analizirana sustava, kavezno je držanje kod 70,83\% ispitanih proizvođača, glavni izvor prihoda kućanstva. Slobodni je sustav držanja i proizvodnje jaja u istome najzastupljeniji kao dopunski izvor prihoda kućanstva, s udjelom od 47,06\%. Poljoprivredna gospodarstva na kojima je proizvodnja organizirana u jednom od alternativnih sustava, odnosno u slobodnome, stajskome koji podrazumijeva volijere ili ekološkome sustavu držanja, svoju strategiju razvoja mogu pronaći u diversifikaciji poslovanja. Kombinacijom nekoliko različitih linija proizvodnje i pružanjem usluga na gospodarstvu moguće je postići raznovrsnost izvora prihoda i njihov ravnomjerniji priljev što će umanjiti rizik poslovanja.
\end{abstract}

Ključne riječi: proizvodnja jaja, obiteljsko poljoprivredno gospodarstvo, diversifikacija poslovanja

\section{Uvod}

U Republici Hrvatskoj proizvodnja peradi najvećim je dijelom organizirana na velikim proizvodnim jedinicama koje u proizvodnji mesa i jaja koriste genetski potencijal peradi koji omogućava visoku proizvodnju (Kralik i sur., 2014.) i koji su u vlasništvu nekolicine proizvođača. Takva intenzivna proizvodnja jaja pokriva $70 \%$ tržišnih potreba, a oko $30 \%$ proizvedenih jaja je iz ekstenzivne proizvodnje, organizirane na manjim proizvodnim jedinicama ili čak kućanstvima (Tolušić, 2011.). Proizvodnja konzumnih jaja u Republici Hrvatskoj do 2012. godine bila je orijentirana na sustav držanja kokoši nesilica u konvencionalnim kavezima, a isti su mogli biti u uporabi najkasnije 12 mjeseci nakon pristupanja Hrvatske Europskoj Uniji. Nakon toga proizvođači su se opredijelili za proizvodnju konzumnih jaja u slobodnim sistemima s velikim ispustima, poluintenzivno držanje s manjim ispustima, podni sistem držanja na dubokoj stelji, stajski ili etažni sustav držanja u nastambi - volijere ili obogaćene kaveze (Kralik i sur., 2013.). Obzirom na navedeno, cilj rada bio je analizirati povezanost organizacijske strukture gospodarstva $\mathrm{s}$ načinom držanja nesilica kako bi se utvrdile razvojne perspektive proizvodnih subjekata.

Dr.sc. Ana Crnčan, izv.prof.dr.sc. Igor Kralik, dr.sc. Jelena Kristić, Poljoprivredni fakultet u Osijeku, Sveučilište J.J. Strossmayera u Osijeku, Vladimira Preloga 1, 31000 Osijek, Hrvatska

Doc.dr.sc. Lari Hadelan, Sveučilište u Zagrebu Agronomski fakultet, Svetošimunska cesta 25, 10000 Zagreb, Hrvatska

Dopisni autor/Corresponding author: dr.sc. Ana Crnčan; e-mail: acrncan@pfos.hr 


\section{Materijal i metode rada}

U radu je za prikupljanje podataka o proizvodno-organizacijskim obilježjima proizvođača konzumnih jaja korištena metoda ankete. Ispitivanje je obuhvatilo proizvođače konzumnih jaja upisane u Upisnik farmi kokoši nesilica na području Republike Hrvatske, prema kojoj je bilo evidentirano 79 proizvođača s kapacitetom od 150 do 259.200 komada nesilica. Navedeni broj odnosi se na proizvođače koji su godinu dana nakon pristupanja Republike Hrvatske Europskoj uniji prilagodili proizvodnju zakonskoj regulativi i time čine osnovni uzorak istraživanja. U ispitivanju je aktivno sudjelovalo 42 proizvođača što čini odaziv od $53 \%$. Od ukupnog broja evidentiranih proizvođača, dva su navela da ne proizvode konzumna jaja, već jaja za rasplod, dok jedan evidentiran proizvođač nije imao navedenu cjelovitu adresu, time i nemogućnost kontakta $\mathrm{s}$ istim. Na temelju prikupljenih podataka o proizvodnoorganizacijskim obilježjima identificirani su čimbenici proizvodnje jaja na proizvodnim jedinicama, te su utvrđene mogućnosti razvoja spomenutih subjekata.

\section{Rezultati i rasprava}

Prema dobivenim podacima najviše ispitanih proizvođača, njih ukupno 19 , proizvodi jaja u kaveznome sustavu držanja s prosječnim brojem od 30.421 nesilica (Tablica 1.). Na navedeni sustav držanja odnosi se i najveći raspon između najmanjeg i najvećeg broja životinja. Tako je najveći broj nesilica čak 220000 kod proizvođača u kaveznome sustavu držanja.

Tablica 1. Prosječan broj životinja u pojedinom sustavu držanja

Table 1 Average number of animals kept in a specific keeping system

\begin{tabular}{lccccc}
\hline $\begin{array}{l}\text { Sustavi } \\
\text { držanja }\end{array}$ & $\begin{array}{c}\text { Broj } \\
\text { proizvođača }\end{array}$ & Prosjek & Medijan & $\begin{array}{c}\text { Najmanja } \\
\text { vrijednost }\end{array}$ & $\begin{array}{c}\text { Najveća } \\
\text { vrijednost }\end{array}$ \\
\hline Kavezni & 19 & 30421 & 10300 & 552 & 220000 \\
Stajski & 11 & 3255 & 1200 & 200 & 15454 \\
Slobodni & 11 & 1496 & 1000 & 140 & 5500 \\
\hline
\end{tabular}

Slobodni i stajski način držanja, u odnosu na kavezni, karakterizira manji broj nesilica, ali i proizvođača, pa je u slobodnome držanju najveći broj životinja kod jednog proizvođača bio 5500. U Tablici 1. nisu navedeni podaci za ekološki sustav držanja, jer se isti odnose na samo jednoga proizvođača na području Republike Hrvatske, a koji ima ukupno 150 nesilica.

Temeljem Zakona o poljoprivredi, poljoprivredna se proizvodnja može obavljati na poljoprivrednom gospodarstvu kao proizvodno-gospodarskoj jedinici koja se bavi poljoprivredom (Ranogajec, 2009.), a djeluje kao: obiteljsko poljoprivredno gospodarstvo, trgovačko društvo, obrt i zadruga. Broj obiteljskih poljoprivrednih gospodarstava u Republici Hrvatskoj upisanih u Upisnik poljoprivrednih gospodarstava 2015. godine bio je 176092 (Agencija za plaćanje u poljoprivredi, 2015.). Prema organizacijskom obliku, obiteljska poljoprivredna gospodarstva u Republici Hrvatskoj čine 97\% u odnosu na broj ukupnih poljoprivrednih gospodarstava. Udio gospodarstva ustrojenih kao obrt je 1,7\%, trgovačka društva čine $1,5 \%$, a na zadružno poslovanje odnosi se samo $0,3 \%$ ukupnih poljoprivrednih gospodarstava (Horvat, 2014.). Struktura proizvodnje jaja, kao i vrsta gospodarstva, odnosno proizvođača, mogu se podijeliti na sljedeće (Tolušić, 2007.): proizvodnja na obiteljskim gospodarstvima ustrojenima kao obrt ili obiteljsko poljoprivredno gospodarstvo, intenzivna 
proizvodnja na velikim farmama i proizvodnim subjektima koju najčešće čine trgovačka društva i ekstenzivna ili seoska proizvodnja i prodaja na okućnicama.

Sukladno prethodno navedenoj klasifikaciji, a prema rezultatima anketnog istraživanja prikazanih u Tablici 2., najveći broj gospodarstava, 38,10\%, djelatnost proizvodnje jaja obavlja kao samostalna gospodarska jedinica temeljena na vlasništvu i uporabi proizvodnih resursa, odnosno kao obiteljsko poljoprivredno gospodarstvo. Taj se podatak može povezati s činjenicom da obiteljska poljoprivredna gospodarstva predstavljaju osnovu poljoprivrede $u$ Republici Hrvatskoj, a njihove osobitosti su sljedeće: proizvodnjom manjih količina jaja mogu podmiriti onaj dio potražnje koje veliki proizvođači ne mogu. Obzirom da na jedinicama ustrojenima kao obiteljsko poljoprivredno gospodarstvo prevladava držanje nesilica $u$ slobodnome (50\%) sustavu držanja, ovi proizvođači se samim načinom proizvodnje diferenciraju od proizvodnje jaja u kavezima. Takva poljoprivredna gospodarstva su zbog svoje veličine i fleksibilnija, što im omogućuje elastičniju ponudu. Naime, „lakše“ će se gospodarstva koja imaju nekoliko tisuća nesilica prilagoditi novonastalim potrebama tržišta $u$ usporedbi sa proizvođačima koji raspolažu kapacitetima od nekoliko stotina tisuća nesilica. Takve prilagodbe u pravilu iziskuju velika financijska izdavanja i provode se duži vremenski period. Također, ekonomski potencijal za samostalno preuzimanje rizika u proizvodnji potiče manje gospodarske subjekte da se elastično povezuju i umrežavaju radi ostvarivanja uspješnijeg zajedničkog poslovanja i podjele rizika.

Tablica 2. Organizacijski oblici proizvodno-gospodarske djelatnosti anketiranih proizvođača Table 2 Organizational forms of production at agricultural farms of surveyed producers

\begin{tabular}{|c|c|c|c|c|c|c|}
\hline \multirow{2}{*}{\multicolumn{2}{|c|}{$\begin{array}{l}\text { Organizacijski oblici } \\
\text { djelatnosti }\end{array}$}} & \multicolumn{5}{|c|}{ Sustavi držanja } \\
\hline & & Kavezni & Stajski & Slobodni & Ekološki & Ukupno \\
\hline \multirow{3}{*}{ OPG } & Broj proizvođača & 2 & 5 & 8 & 1 & 16 \\
\hline & $\begin{array}{l}\text { Udio u ukupnom broju } \\
\text { proizvođača }(\%)\end{array}$ & 4,76 & 11,90 & 19,05 & 2,38 & 38,10 \\
\hline & $\begin{array}{l}\text { Udio u org. obliku } \\
\text { djelatnosti }(\%)\end{array}$ & 12,50 & 31,25 & 50,00 & 6,25 & 100 \\
\hline \multirow{3}{*}{ Obrt } & Broj proizvođača & 10 & 4 & 1 & 0 & 15 \\
\hline & $\begin{array}{l}\text { Udio u ukupnom broju } \\
\text { proizvođača }(\%)\end{array}$ & 23,81 & 9,52 & 2,38 & 0,00 & 35,71 \\
\hline & $\begin{array}{l}\text { Udio u org. obliku } \\
\text { djelatnosti }(\%)\end{array}$ & 66,67 & 26,67 & 6,67 & 0,00 & 100 \\
\hline \multirow{3}{*}{$\begin{array}{l}\text { Trgovačko } \\
\text { društvo }\end{array}$} & Broj proizvođača & 7 & 2 & 2 & 0 & 11 \\
\hline & $\begin{array}{l}\text { Udio u ukupnom broju } \\
\text { proizvođača }(\%)\end{array}$ & 16,67 & 7,76 & 4,76 & 0,00 & 26,19 \\
\hline & $\begin{array}{l}\text { Udio u org. obliku } \\
\text { djelatnosti }(\%)\end{array}$ & 63,64 & 18,18 & 18,18 & 0,00 & 100 \\
\hline \multirow{2}{*}{ Ukupno } & Broj proizvođača & 19 & 11 & 11 & 1 & 42 \\
\hline & Ukupno $(\%)$ & 45,24 & 26,19 & 26,19 & 2,38 & 100 \\
\hline
\end{tabular}


Učestalost pojedinog sustava držanja statistički se značajno razlikovala ovisno o organizacijskom obliku gospodarstva $(\mathrm{p}=0,0112)$. U strukturi sustava držanja na OPG-ima su najzastupljeniji slobodni $(50,00 \%)$ i stajski uzgoj $(31,25 \%)$, dok je pri gospodarstvima ustrojenima kao obrt i trgovačko društvo najučestalija proizvodnja jaja u kaveznome sustavu držanja (66,67\%, odnosno 63,64\%).

U Tablici 3. prikazano je razvrstavanje proizvođača prema izvorima prihoda gospodarstva, tako da manji dio, njih 41,46\%, ostvaruju prihode proizvodnjom i prodajom jaja kao dopunskom djelatnosti pored još jedne djelatnosti. Dok je kod većine proizvođača $(58,54 \%)$ mjesečni prihod gospodarstva vezan uz proizvodnju jaja kao glavnim izvorom prihoda.

Tablica 3. Osnovni izvor prihoda gospodarstva prema sustavu držanja

Table 3 Basic sources of income of agricultural farm according to the keeping system

\begin{tabular}{|c|c|c|c|c|c|c|}
\hline \multirow{2}{*}{\multicolumn{2}{|c|}{$\begin{array}{l}\text { Izvor prihoda } \\
\text { gospodarstva }\end{array}$}} & \multicolumn{5}{|c|}{ Sustavi držanja } \\
\hline & & Kavezni & Stajski & Slobodni & Ekološki & Ukupno \\
\hline \multirow{3}{*}{ Glavni } & Broj gospodarstava & 17 & 4 & 3 & 0 & 24 \\
\hline & $\begin{array}{l}\text { Udio u ukupnom broju } \\
\text { gospodarstava }(\%)\end{array}$ & 41,46 & 9,76 & 7,32 & 0,00 & 58,54 \\
\hline & $\begin{array}{l}\text { Udio prema izvoru } \\
\text { prihoda }(\%)\end{array}$ & 70,83 & 16,67 & 12,50 & 0,00 & 100 \\
\hline \multirow{3}{*}{ Dopunski } & Broj gospodarstava & 2 & 6 & 8 & 1 & 17 \\
\hline & $\begin{array}{l}\text { Udio u ukupnom broju } \\
\text { gospodarstava }(\%)\end{array}$ & 4,88 & 14,63 & 19,51 & 2,44 & 41,46 \\
\hline & $\begin{array}{l}\text { Udio prema izvoru prihoda } \\
(\%)\end{array}$ & 11,76 & 35,29 & 47,06 & 5,88 & 100 \\
\hline \multirow{2}{*}{ Ukupno } & Broj gospodarstava & 19 & 10 & 11 & 1 & 41 \\
\hline & Ukupno (\%) & 46,34 & 24,39 & 26,83 & 2,44 & 100 \\
\hline \multicolumn{5}{|c|}{ Bez odgovora } & & 1 \\
\hline
\end{tabular}

Od analiziranih sustava držanja, kavezno je kod 70,83\% ispitanih proizvođača, isključivo, glavni izvor prihoda kućanstva, dok je slobodni sustav držanja i proizvodnje jaja u istome najzastupljeniji kao dopunski izvor prihoda kućanstva, s udjelom od 47,06\%.

Prema podacima iz Tablice 2. koja prikazuje organizacijske oblike gospodarstava i Tablice 3. koja prikazuje izvor prihoda gospodarstva prema sustavu držanja, može se zaključiti kako slobodni i stajski sustav držanja prevladava na obiteljskim poljoprivrednim gospodarstvima i uglavnom predstavlja dopunski izvor prihoda gospodarstva. Prodaja jaja pri kojem je proizvodnja jaja organizirana u obogaćenim kavezima, uglavnom predstavlja glavni izvor prihoda gospodarstva. Ovime je potvrđeno kako je u Republici Hrvatskoj proizvodnja peradi najvećim dijelom organizirana na velikim proizvodnim jedinicama koje su u vlasništvu nekolicine proizvođača i kako takva intenzivna proizvodnja jaja pokriva većinu tržišnih potreba, dok manji dio proizvedenih jaja je iz ekstenzivne proizvodnje organizirane na manjim proizvodnim jedinicama. Postizanje ekonomske uspješnosti koja će biti iskazivana razinom 
dodatne vrijednosti obiteljskih poljoprivrednih gospodarstva i obrta u proizvodnji jaja moguće je stvoriti osmišljavanjem ponude proizvoda koji su superiorniji od onih koji su na tržištu raspoloživi (Deže i sur., 2008.). Manja poljoprivreda gospodarstva koja proizvode jaja u alternativnim sustavima, odnosno u slobodnome, stajskome koji podrazumijeva volijere ili ekološkome sustavu držanja, svoju strategiju razvoja mogu pronaći u diversifikaciji poslovanja (Crnčan i sur., 2014.). Ono se može odnositi na širenje proizvodnje kroz uzgoj autohtonih pasmina kao što su kokoši Hrvatice i razvoj usluga kroz ruralni turizam na obiteljskim poljoprivrednim gospodarstvima. Najvažnija komponenta za razvoj navedenih aktivnosti svakako je prirodno-ekološka okolina. Upravo ova prirodna resursna osnovica je ta koja uvelike diferencira male proizvođače koji proizvode jaja u alternativnim sustavima od velikih proizvođača jaja. Kombinacijom nekoliko različitih linija proizvodnje i usluga na gospodarstvu moguće je postići raznovrsnost izvora prihoda i njihov ravnomjerniji priljev što umanjuje rizik poslovanja koji je osobito važan u današnjem nesigurnom okruženju (Horvat i Kovačić, 2004). Iz dodatnih aktivnosti koje se odnose na osmišljavanje i širenje ponude proizvoda, te razvoj usluga na obiteljskim poljoprivrednim gospodarstvima proizlaze prednosti manjih proizvodnih subjekata čija je djelatnost proizvodnja jaja. Jednostavnije prilagođavanje proizvodnih resursa i stvaranje dopunskih aktivnosti na gospodarstvu ujedno generira mogućnost obiteljskog zapošljavanja, a time i veću mogućnost neovisnosti i financijske uspješnosti.

\section{Zaključci}

Najveći broj gospodarstava, 38,10\%, djelatnost proizvodnje jaja obavlja kao samostalna gospodarska jedinica, odnosno kao obiteljsko poljoprivredno gospodarstvo na kojemu prevladava držanje nesilica u slobodnome (50\%) sustavu držanja. Od analiziranih sustava, kavezno je držanje kod 70,83\% ispitanih proizvođača, isključivo, glavni izvor prihoda kućanstva, dok je slobodni sustav držanja i proizvodnja jaja u istome najzastupljeniji kao dopunski izvor prihoda kućanstva s udjelom od 47,06\%. Manja poljoprivredna gospodarstva koja proizvode jaja u alternativnim sustavima, odnosno u slobodnome ili ekološkome sustavu držanja, svoju strategiju razvoja mogu pronaći u diversifikaciji poslovanja koja podrazumijeva širenje proizvodnje i razvoj turističkih usluga na obiteljskim poljoprivrednim gospodarstvima. Kroz organizaciju poslovanja koja podrazumijeva dopunske aktivnosti na gospodarstvu stvara se mogućnost i obiteljskog zapošljavanja, veće neovisnosti i izvjesnije poslovne uspješnosti.

\section{LITERATURA}

1. Agencija za plaćanje u poljoprivredi (2015): Broj OPG-a prema spolu i godinama nositelja. www.apprrr.hr/upisnik-poljoprivrednih-gospodarstava-1149.aspx (03.03.2017.).

2. Crnčan, A., Kristić, J., Zmaić, K. (2014): Impact of EU regulations on investments in Croatian table egg production and its competitiveness, Bulgarian Journal of Agricultural Science, 4(20): 734-737.

3. Deže, J., Kanisek, J., Ranogajec, Lj., Tolušić, Z., Lončarić, R., Zmaić, K., Tolić, S., Sudarić, T., Kralik, I., Turkalj, D., Kristić, J., Crnčan, A. (2008): Agroekonomika. Osječko-baranjska županija, Osijek.

4. Horvat, Đ., Kovačić, M. (2004): Menadžment u malom poduzetništvu. Cera Prom, M.E.P. Consult, Zagreb. 
5. Horvat, H. (2014): Budućnost hrvatskih obiteljskih poljoprivrednih gospodarstava. www.mps.hr/UserDocsImages/IYFF/Budu\%C4\%87nost\%20hrvatskih\%20obiteljskih\%20PG-a.pdf (03.03.2017.).

6. Kralik, G., Janječić, Z., Kralik, Z., Škrtić, Z. (2013): Stanje u peradarstvu i trendovi njegova razvoja, Poljoprivreda, 19(2): 49-58.

7. Kralik, I., Kralik, Z., Zelić, S. (2014): Preferencije potrošača konzumnih jaja. Zbornik radova 49. hrvatskog i 9. međunarodnog simpozija agronoma. Opatija, 16.-21.02.2014., str. 156-160.

8. Ranogajec, Lj. (2009): Računovodstvo u poljoprivredi. Poljoprivredni fakultet u Osijeku, Osijek.

9. Tolušić, Z. (2007): Tržište i distribucija poljoprivredno-prehrambenih proizvoda. Poljoprivredni fakultet u Osijeku, Osijek.

10. Tolušić, Z. (2011): Tržište i distribucija poljoprivredno-prehrambenih proizvoda. II. dopunjeno i izmijenjeno izdanje. Poljoprivredni fakultet u Osijeku, Osijek.

\section{ORGANIZATIONAL CHARACTERISTICS OF TABLE EGG PRODUCERS IN CROATIA}

\section{Summary}

The aim of this research was to analyze the production and organizational structure of agricultural family farms specialized in production of eggs, in order to determine their development perspective. Data on production and organizational characteristics were collected by a survey. The survey involved table egg producers entered in the Register on laying hens' farms in Croatia. The greatest number of farms, $38.10 \%$, produces eggs as an independent economic unit based on the ownership and on usage of production resources, i.e. as an agricultural family farm. Out of four analyzed systems, cage-keeping system was the main source of household income for $70.83 \%$ of the surveyed egg producers. Free-range hens' keeping and egg production is the most represented supplementary source of household income, with a portion of $47.06 \%$. Agricultural farms that organize egg production in alternative systems, i.e. in free-range indoor system, in aviaries or in organic system, direct their development strategy towards the diversification of business venture. By combining several different production systems and by providing services, agricultural farms can achieve a variety of income sources and assure constant income inflow, thus reducing the business risks.

Key words: egg production, agricultural family farm, diversification of business venture

Primljeno - Received: 23.04.2017.

Prihvaćeno - Accepted: 05.07.2017. 